\title{
A INFLUÊNCIA DO SISTEMA REMOTO NO ENSINO DA DISCIPLINA DE METODOLOGIA CIENTÍFICA AOS ALUNOS DO CURSO DE ENGENHARIA DE MINAS DA UFOP
}

DOI: 10.37702/2175-957X.COBENGE.2021.3541

Caio Cesar Gonzaga Alves - caioalvesbnk@gmail.com

Universidade Federal de Ouro Preto

Luis pereira de souza 88

36204-422 - Barbacena - MG

Paulo Henrique Liberato da Silva - paulo.liberato@aluno.ufop.edu.br

Universidade Federal de Ouro Preto

Rua Arthur Versiani Machado 590

35400-000 - Ouro Preto - MG

Thiago Duarte Figueiredo - thiagoduarte1926@gmail.com

Universidade Federal de Ouro Preto

Rua Pedro Alexandrino Rufino 76

35400-000 - OURO PRETO - MG

Gabriela de oliveira Brito - gabriela.brito@aluno.ufop.edu.br

Universidade Federal de Ouro Preto

Rua Antonio José Ramos 228

35400-000 - Ouro Preto - MG

Carlos Alberto Pereira - pereiraufop@gmail.com

Universidade Federal de Ouro Preto

Rua João XXIII 240

35400-000 - Ouro Preto - MG

Resumo: No curso de engenharia de minas da universidade federal de ouro preto a disciplina de metodologia científica consiste em uma das mais importantes ferramentas de aprimoramento da escrita científica e apresentação dos alunos à pesquisa acadêmica. Sendo fundamental no desenvolvimento do aluno, o Ensino da disciplina foi significativamente afetado pelo isolamento social provocado pela pandemia e pela consequente implementação do período letivo especial (PLE), 
com aulas virtuais e ensino de forma remota. Assim, o artigo visa avaliar as mudanças geradas pelo Ensino remoto e o impacto do mesmo no aprendizado dos alunos. Por meio de um questionário enviado após o período letivo aos discentes e consulta ao professor da disciplina, foi realizado o levantamento de dados e análise do discurso do sujeito coletivo a partir das respostas obtidas, destacando o ponto de vista dos próprios consultados. As respostas dos alunos evidenciaram fatores limitantes a qualidade do Ensino, como a falta de conexão satisfatória de internet, de horários para estudo e de ambientes adequados para o acompanhamento das atividades. Além disso, destacou-se a insegurança provocada pelo isolamento social, atrapalhando o rendimento dos discentes. Contudo, foi observado que a produtividade da turma permaneceu satisfatória, assim como os próprios discentes confirmaram que o PLE não influenciou significativamente sua produtividade, mesmo com o aumento no numero de reprovados. Por fim, foi sugerida a adoção de mais aulas assíncronas, flexibilização de prazos e um acompanhamento mais próximo por parte da instituição de Ensino em relação aos alunos, principalmente em relação a saúde mental dos mesmos.

Palavras-chave: Metodologia científica, aprendizagem eletrônica, métodos de ensino 


\section{(c) COBENGE \\ A INFLUÊNCIA DO SISTEMA REMOTO NO ENSINO DA DISCIPLINA DE METODOLOGIA CIENTÍFICA AOS ALUNOS DO CURSO DE ENGENHARIA DE MINAS DA UFOP}

\section{INTRODUÇÃO}

A disciplina de Metodologia Cientifica e suas derivações consistem na revisão das ferramentas, técnicas e diferentes abordagens empregados para a realização de qualquer pesquisa científica (OLIVEIRA e VALENÇA, 2015). Tal conteúdo consiste em ferramenta importante no desenvolvimento dos alunos dos cursos de graduação, especialmente nos períodos iniciais do ensino superior, onde muitas vezes os discentes são inseridos no meio acadêmico advindos de um ensino médio incapaz de fornecer conhecimentos suficientes envolvendo a elaboração de pesquisa, a escrita científica e a comunicação técnica.

Sendo assim, o estudo destes conceitos ajuda os alunos a melhorarem a maneira de apresentarem as suas ideias sobre assuntos determinados, ajudando-os a organizarem os pensamentos na hora da leitura e escrita, deixando-os confiantes para produzir textos e transmitir informações com clareza, coerência, e precisão, se tornando inclusive, peça importante no combate ao plágio (GUEDES et al., 2018). Dessa forma, embora nos cursos de engenharia a Metodologia Científica é muitas vezes vista como uma disciplina de menor importância e com ausência de discussões a respeito de seus conceitos e aplicações (VIEIRA, et al., 2017), a disciplina apresenta pontos importantes que ultrapassam os limites da sala de aula e se tornam diferenciais para o sucesso profissional dos alunos.

$\mathrm{Na}$ Universidade Federal de Ouro Preto, mais precisamente no curso de Engenharia de Minas, as aulas de Metodologia Científica são lecionadas desde o ano de 2013, seguindo as Diretrizes Curriculares Nacionais (SILVA et, al., 2020). A disciplina busca promover, além do desenvolvimento do aluno a partir da formulação de textos, apresentação de trabalhos em público e o contato com diversos gêneros textuais, também a interação do estudante com outras áreas da graduação como a extensão e a pesquisa. Destaca-se também a proposta de elaboração de um artigo por semestre a fim de induzir o discente à prática dos conteúdos abordados, e, quem sabe, despertar o interesse do mesmo pela pesquisa.

$\mathrm{Na}$ UFOP, assim como em grande parte das entidades estudantis, a disciplina de Metodologia Científica era aplicada por métodos convencionais de ensino, com a presença física dos alunos e professores em sala de aula, prática que até então, na visão tanto de alunos quanto dos professores, sempre garantiu bons resultados, com desenvolvimento significativo dos alunos. Contudo, a pandemia causada pelo novo coronavírus, trouxe uma nova realidade para o ensino da disciplina na UFOP e nas demais universidades. fazendose necessário o isolamento social e impossibilitando a continuidade das aulas presenciais e dos métodos tradicionais de ensino.

Como afirmam Pasini, Carvalho e Almeida (2020), a crise sanitária promoveu uma revolução no sistema educacional, exigindo a ressignificação de conceitos consolidados. Mudanças significativas foram necessárias para adaptação ao novo modo de lecionar as disciplinas, como a de Metodologia Científica. A necessidade de adaptação repentina por parte dos alunos e professores aos novos moldes de ensino trouxe consigo a implantação do ensino ábdito por parte das universidades, com o desenvolvimento das disciplinas de forma virtual, por meio de reuniões online e atividades síncronas e assíncronas, sem contato direto entre professores e alunos, constituindo assim o período letivo especial (PLE) 
Ocorre que, apesar dessa nova realidade de início ter demonstrado ser temerária, devido à incerteza de como seriam as aulas e qual seria o retorno obtido, a necessidade de tal adaptação trouxe possibilidades até então pouco exploradas, como o uso de novas tecnologias no ensino. No entanto, tais mudanças implicam em dilemas como a necessidade de garantia de comunicação efetiva e de disponibilidade de insumos suficientes para os alunos que permitam o acompanhamento das aulas, assim como o a adaptação necessária à cultura digital por parte dos alunos e professores.

Dessa forma, por se tratar de uma metodologia nova, implementada de forma repentina e ainda em adaptação, se faz necessário o levantamento de dados e a avaliação após o primeiro período de ensino remoto para que seja analisado o impacto do EAD na aprendizagem dos conteúdos abordados na disciplina. Assim, visando todas as questões levantadas acima, o artigo busca avaliar a implementação da disciplina Metodologia Científica na UFOP no curso de Engenharia de Minas com o ensino remoto, descrevendo as principais mudanças, novos desafios, pontos positivos e negativos e qual a visão dos alunos e professor em relação ao período lecionado, buscando também utilizar esse apanhado para uma análise global.

\section{METODOLOGIA}

A fim de mensurar o aprendizado e opiniões dos alunos participantes do PLE (Período Letivo Especial) em relação à nova metodologia de ensino empregada, foi elaborado um questionário, o qual foi enviado à turma de Engenharia de Minas participante da disciplina de Metodologia Científica via e-mail institucional dos alunos.

O questionário foi elaborado com o auxílio do aplicativo Google Forms, pelo qual foram elaboradas 2 questões discursivas e 4 de múltipla escolha, onde foram obtidas 25 respostas. Por meio do formulário as respostas dos alunos foram reunidas e analisadas pelo método do discurso do sujeito coletivo (DSC), ferramenta que consiste no agrupamento dos depoimentos com ideias semelhantes e reescrita dos mesmos na forma de discursos-síntese que representam o estrato dos depoimentos analisados. As respostas de múltipla escolha foram analisadas e discutidas por meio da análise gráfica dos valores obtidos.

Além do questionário aplicado aos alunos, foi realizada uma consulta ao docente da disciplina de Metodologia Científica a fim de registrar o ponto de vista do professor em relação à disciplina e a sua aplicação nos moldes do PLE, assim como todas as mudanças necessárias na forma de abordar os conteúdos, se relacionar com os alunos e avaliar o desempenho dos mesmos. A entrevista se baseou na discussão de temas condizentes à importância da disciplina de Metodologia Científica para o desenvolvimento dos alunos e sobre as mudanças observadas pelo docente em relação às aulas lecionadas na forma presencial e durante o ensino remoto.

\section{RESULTADOS E DISCUSSÃO}

A disciplina de Metodologia Científica foi lecionada para os alunos do curso de engenharia de minas da UFOP durante o período de 24/08/20 a 17/10/20, de forma virtual por meio de encontros semanais pela plataforma google meet. O número de alunos matriculados foi de 41 discentes, dos quais 25 foram aprovados de forma direta, 3 após exame especial e 13 alunos foram reprovados, totalizando um índice de $61 \%$ de aprovação. 
Observa uma queda no índice de aprovação da disciplina em relação aos obtidos nos períodos anteriores, cujo ensino era realizado de maneira presencial. Considera-se que o PLE influenciou tal estatística, principalmente em relação a evasão de parte da turma devido a fatores como dificuldade de acompanhamento das aulas por questões de conexão de internet e frustração dos alunos pela transformação radical nos modos de vida e estudo, desmotivando-os, comprometendo a absorção do conteúdo aplicado e o foco dos mesmos nas aulas online.

Ao longo das 8 semanas da disciplina foi proposta a realização de atividades semanais para entrega quinzenal, com a abertura de horários alternativos para auxílio aos alunos e resolução de dúvidas a respeito da realização das atividades, com a participação de monitores. Observou-se que houve uma demanda elevada de apoio aos alunos na realização das atividades, evidenciando, como citado anteriormente, uma maior dificuldade por parte dos mesmos em se adaptar ao ensino remoto e absorver de forma sólida os conteúdos abordados.

\subsection{Avaliação por parte dos alunos}

Analisando as respostas obtidas pelo formulário aplicado aos alunos é possível avaliar tal cenário, levantando os principais pontos de discussão, sejam eles positivos ou negativos. Sendo assim, a primeira questão abordada buscou mensurar na visão dos alunos sobre o aprendizado obtido durante o ensino remoto da disciplina Metodologia Científica, cujas respostas estão representadas pela Figura 1.

Figura 1 - Avaliação do aprendizado por parte dos alunos.

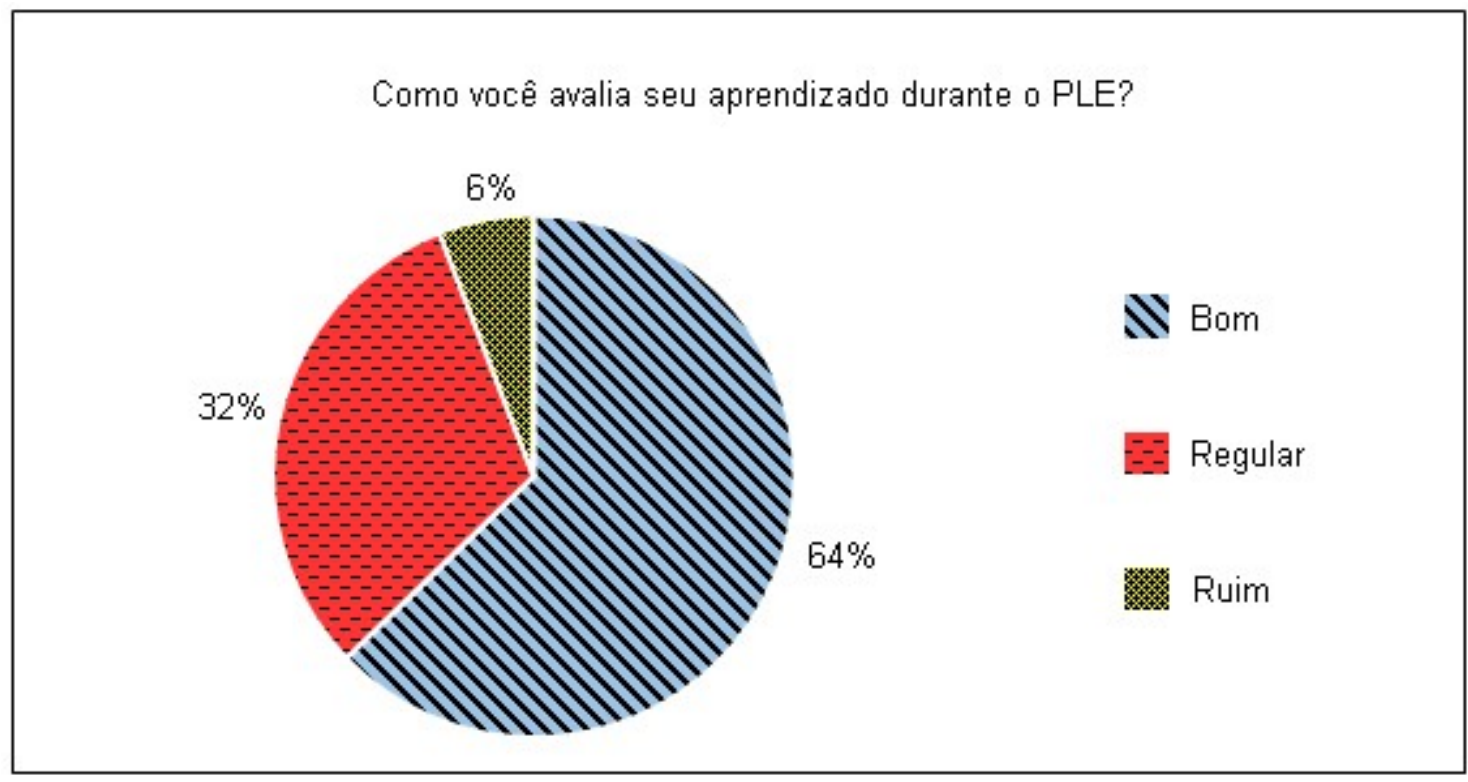

Fonte: Autoria própria

Observa-se que a maior parte dos alunos considerou como bom o aprendizado do conteúdo abordado ao longo do ensino remoto. No entanto, deve-se destacar que apesar de representar a menor parte dos alunos, a porcentagem de estudantes que avaliou o aprendizado como regular ou ruim representa mais que um terço da turma, número significativo de alunos. Este fato presume uma possível necessidade de adaptações e mudanças em alguns pontos na forma pela qual a disciplina foi abordada, a fim de reduzir o nível de satisfação dos alunos. 
A segunda questão diz respeito ao acompanhamento das aulas por parte dos alunos. Como representa a Figura 2, nota-se que apenas $56 \%$ dos alunos conseguiram estar presentes em todos os encontros, o que não é muito diferente da disciplina oferecida presencial.

Figura 2 - Frequência dos alunos durante as aulas do PLE.

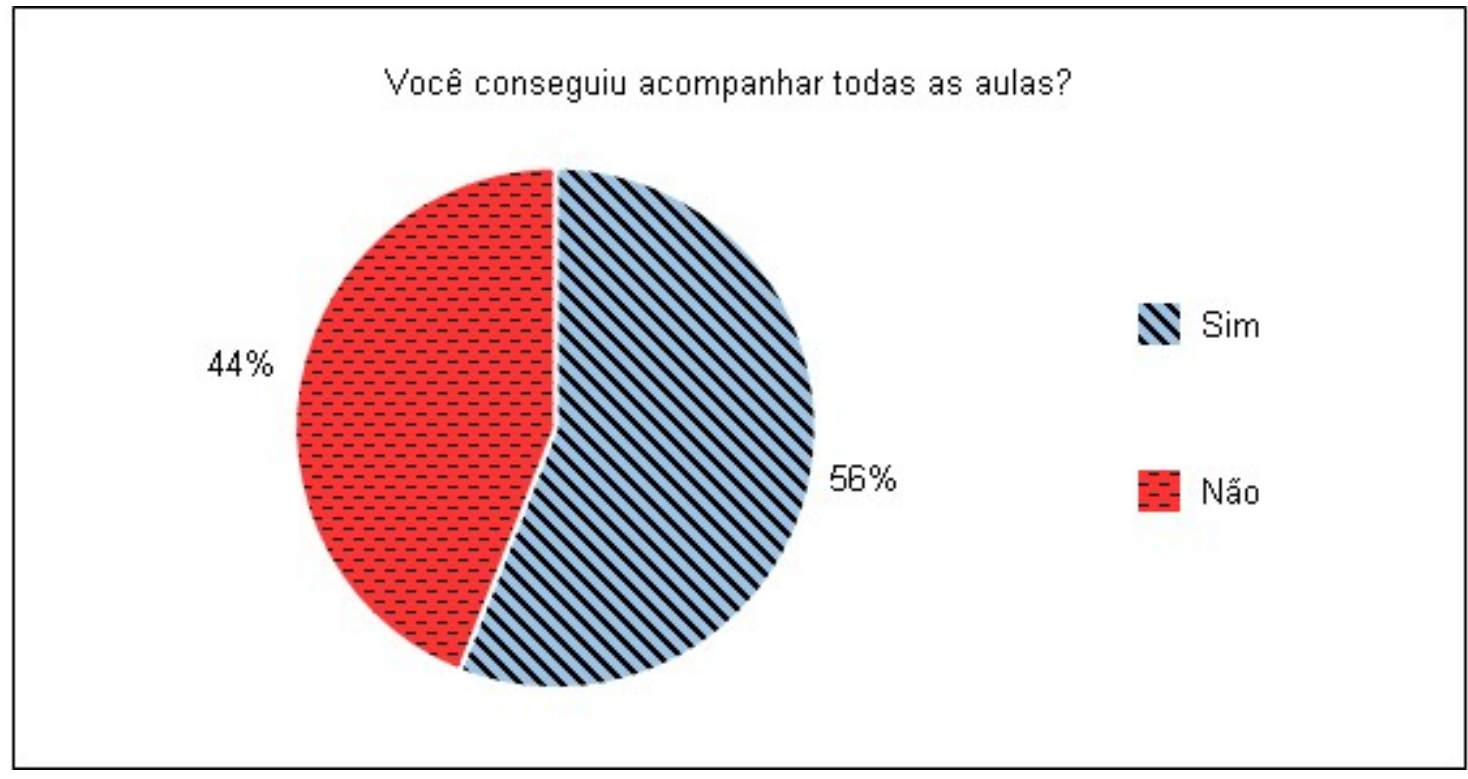

Fonte: Autoria própria

Este número evidencia uma dificuldade por parte dos alunos de se manter uma rotina semelhante à das aulas presenciais, seja por questões de conexão de internet, problemas com os horários e até mesmo o surgimento de outras demandas no mesmo horário, principalmente em relação à família e afazeres de casa. Por estarem em casa, os alunos muitas vezes os familiares exercem uma certa pressão sobre os estudantes, não dando a liberdade e tranquilidade necessária para assistirem as aulas e até mesmo atarefando-os nos horários dos encontros.

Corroborando com o observado, a terceira questão direcionada aos alunos evidencia que $16 \%$ dos alunos sequer possuíam locais adequados para a participação das aulas e do ensino remoto (Figura 3). Isso se deve principalmente ao fato de que em muitos casos, o aluno não possui um local tranquilo e propício para os estudos, seja por não conseguir uma conexão de internet suficientemente boa, barulho por parte de vizinhos, animais ou movimentação nos arredores do local de estudo, não proporcionando demandas essenciais para a concentração dos estudantes. 
Figura 3 - Consulta aos alunos sobre o local de estudos durante o PLE.

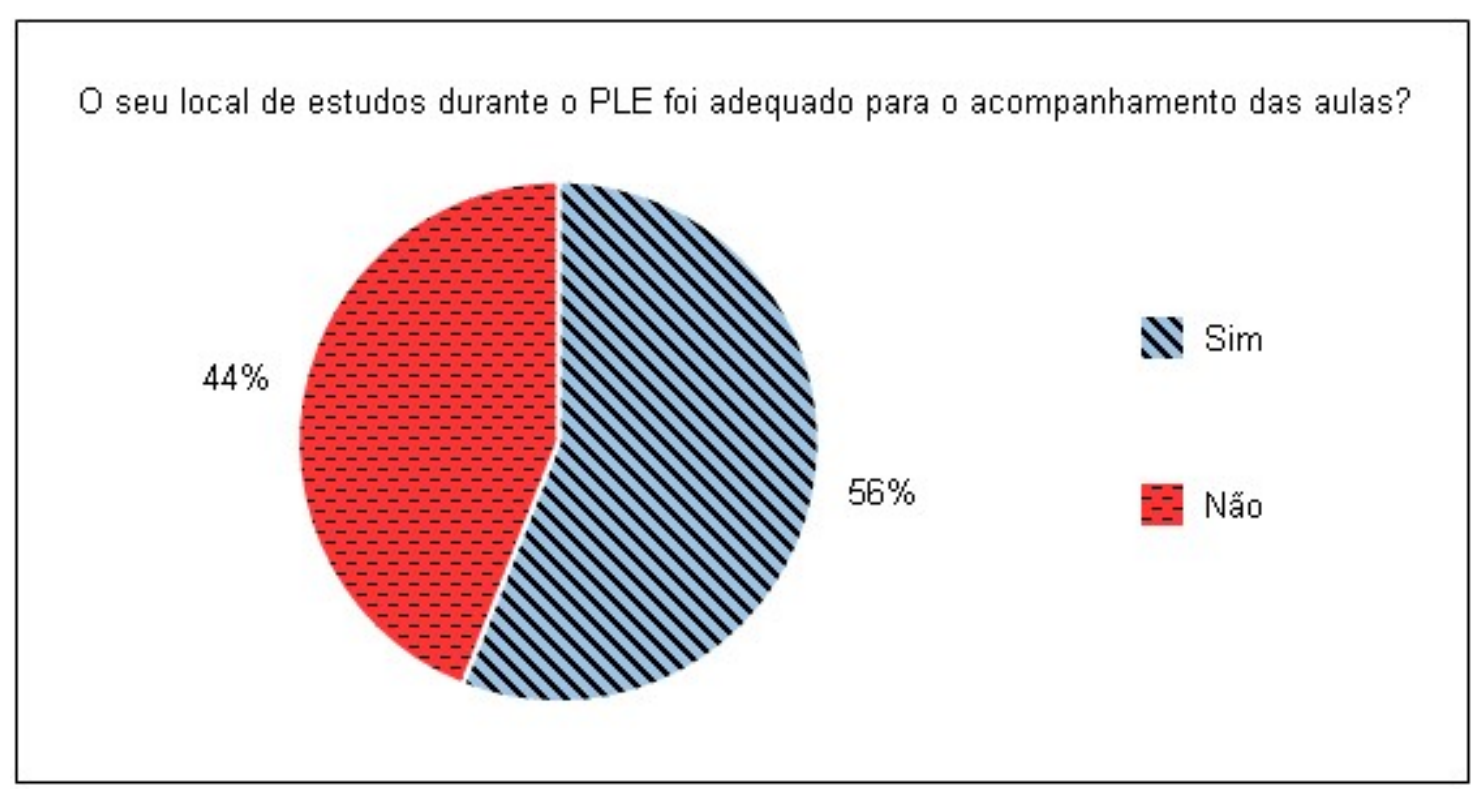

Fonte: Autoria própria

Por fim, a quarta questão aborda a autoanálise por parte dos alunos a respeito das questões emocionais enfrentadas pelos mesmos. A Figura 4 explicita as respostas obtidas, onde observa-se que $16 \%$ dos alunos consultados consideram que sofreram de alguma tribulação emocional durante o ensino remoto.

Figura 4 - Autoavaliação dos alunos sobre suas condições emocionais durante o PLE.

Você teve condiçổes emocionais suficientemente boas para o acompanhamento do PLE?

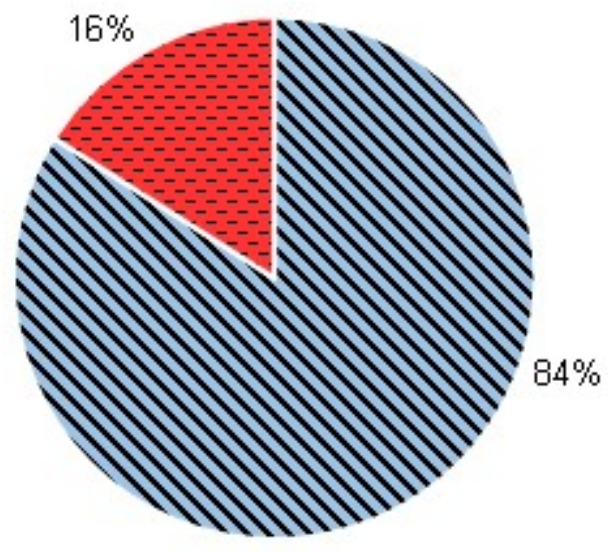

N Sim

Nẵo

Fonte: Autoria própria

Por se tratar de um período em que os alunos se encontram em isolamento social, com rotinas totalmente alteradas em relação às que estão habituados e com grande 
apreensão em relação à pandemia, questões como o foco nos estudos e a adaptação às mudanças de ensino são significativamente mais difíceis que em outras épocas. Ainda se salienta que, embora a maioria dos alunos declare possuir condições emocionais adequadas, é fato que, até para tais, as mudanças no convívio e no estudo impactaram seu modo de pensar e suas emoções.

Dessa forma, observa-se que acima da questão técnica, há a necessidade de se abordar a questão emocional dos alunos, propondo discussões e de certa forma um apoio mútuo para a adaptação mais amena à tantas mudanças ocorridas em tão pouco tempo. Sendo assim, observou-se que a discussão de temas além da disciplina se fez primordial no desenvolvimento dos alunos. Muitas vezes questões como a adaptação ao sistema remoto, o desgaste mental gerado pelo isolamento social e a apreensão sobre o futuro foram discutidas, sendo tão ou até mais importantes para a realização das atividades do que o próprio conteúdo da disciplina.

A partir das respostas discursivas do questionário proposto aos alunos e das discussões realizadas ao longo da disciplina, algumas questões importantes foram levantadas em relação aos problemas enfrentados durante o período letivo especial (PLE). Agrupando as respostas pelo método do discurso do sujeito coletivo (DSC), foi possível concluir que os principais fatores citados como obstáculos ao bom desempenho dos discentes no PLE foram a dificuldade de estabelecer uma rotina de estudos, acarretando numa dificuldade em concentrar durante a aula e a realização das atividades, além da instabilidade da internet e o curto período de duração, acarretando num acúmulo de atividades. Foi observado também que os alunos que foram para a casa dos pais, enfrentam contratempos atrelados à rotina da família, uma vez que foram instruídos a ajudar nos afazeres da casa, em comércios da família e outros locais de trabalho durante o período de realização das aulas virtuais.

Outra questão importante tratada durante as aulas e citada pelos alunos consultados foi a instabilidade emocional dos mesmos, fator que atrapalhou significativamente os estudantes durante as aulas remotas. Os alunos relataram ter problemas relacionados à ansiedade devido ao medo da reprovação, pressão familiar e acúmulo de atividades devido ao curto período de tempo para realizá-las, além da incerteza do futuro.

No questionário aplicado, os alunos tiveram espaço para sugestão de medidas a serem tomadas para tentar atenuar os problemas enfrentados durante a realização das aulas. Dentre as principais iniciativas levantadas, destaca-se a realização de um estudo mais completo sobre a condição social de cada aluno, a fim de garantir a aplicação do auxílio de internet para os mesmos de forma justa e eficaz, evitando fraudes e desassistências a quem realmente necessita do incentivo para ter condições adequadas de acesso à internet e acompanhamento das aulas.

Ao serem questionados sobre o panorama geral do ensino remoto para todas as disciplinas, também foi levantada a questão de uma maior compreensão por parte dos professores, não cobrando atividades muito extensas, pois isso prejudica nas demais disciplinas que estão sendo cursadas e também serem mais flexíveis com os prazos para serem realizadas. Além disso, os alunos sugeriram que o colegiado de cada departamento solicite que os docentes gravem e disponibilizem as aulas síncronas realizadas ao longo do período letivo, a fim de garantir aos alunos o acesso ao conteúdo fora dos horários de aula, visto que como citado anteriormente, alguns alunos não conseguem acompanhar todas as aulas por motivos além do seu alcance.

A realização de palestras e rodas de conversa também foi sugerida, principalmente para acompanhamento dos alunos e acolhimento dos mesmos, a fim de tornar o PLE mais suave e permitir aos estudantes uma melhor adaptação e uma boa saúde mental. 
Por fim, ao consultar os alunos e alguns professores, alguns pontos positivos dessa iniciativa também foram levantados, como a praticidade, o conforto e a segurança promovida pelas aulas remotas, uma vez que o aluno dá sequência a seu curso sem sair de casa e se expor a riscos inerentes ao deslocamento diário. Além disso, destaca-se a possibilidade de alunos assistirem as aulas mesmo que porventura se encontrem em outros locais, permitindo que, alunos realizando estágio em outras cidades, por exemplo, consigam conciliar seu trabalho com a realização das disciplinas, evitando atrasos no processo de formação.

A motivação principal para a implementação do PLE se dá pela necessidade de oferta de disciplinas da graduação para que os alunos não fossem totalmente prejudicados, e tivessem sua jornada acadêmica totalmente interrompida durante o período de isolamento social. Dessa forma, por se tratar de um processo novo e realizado de forma repentina, o PLE apresenta pontos a serem melhorados para possíveis novos períodos não presenciais ou até mesmo para a implementação definitiva do recurso para a aplicação de algumas disciplinas, mas percebe-se que sua aplicação foi válida e de fundamental importância para a manutenção das atividades de educação na engenharia.

Ao consultar o docente responsável pela disciplina de Metodologia Científica na UFOP, o mesmo ressaltou a importância do conteúdo para o desenvolvimento dos alunos e as alterações pelas quais a disciplina foi submetida ao longo dos anos, assim como a qual está acontecendo com a inserção do ensino remoto. Segundo o professor, a disciplina era a princípio lecionada por docentes da área de humanas, que por sua vez possuíam outra abordagem em relação ao tema. Sendo assim, com a alteração para professores da engenharia, o formato da avaliação mudou significativamente, exigindo mais leitura e escrita dos alunos com trabalhos diários, aumentando o contato dos mesmos com a escrita científica, conferindo efeitos importantes no desenvolvimento especialmente dos alunos dos períodos iniciais.

Dessa forma, observa-se que embora as mudanças nos métodos de ensino da disciplina sejam complexas e exijam tempo e esforço para a adaptação dos alunos e professores, tais medidas podem acarretar em efeitos positivos, seja em relação ao aprendizado, à praticidade do ensino e a produtividade dos alunos, podendo se tornar uma alteração permanente caso haja tal conclusão.

O relato do docente em relação à adequação da disciplina ao ensino remoto corrobora tal evidência. Segundo o mesmo, apesar de certa resistência ao método de aulas virtuais, o ensino remoto não provocou queda no desempenho dos alunos, tampouco em prejuízos no empenho e na produtividade dos mesmos, haja vista que artigos feitos pelos próprios alunos têm sido aprovados em congressos com frequência, inclusive na última edição do COBENGE. Para o caso da disciplina de Metodologia Científica, o professor reitera que tanto no ensino presencial como no remoto, os desafios enfrentados são os mesmos, com resultados dependentes da maturidade e do empenho do aluno, variando de pessoa para pessoa e não da forma com que o conteúdo da disciplina é abordado.

\section{CONCLUSÕES}

Após a avaliação dos impactos da implementação do ensino remoto na disciplina de Metodologia Científica foi possível observar o quão desafiador foi, para alunos e professores, se adaptar à nova forma de ensino. A consulta aos alunos evidenciou problemas enfrentados pelos mesmos para o acompanhamento das aulas, como a falta de conexão de internet satisfatória, de locais de estudo apropriados e de disponibilidade de horário para presença nas aulas síncronas, além do fator psicológico, influenciado 
significativamente pelo isolamento social e pela incerteza gerada pela pandemia, tanto no âmbito acadêmico quanto no pessoal. Com isso, observou-se um aumento no índice de reprovados na disciplina.

Como medidas de correção dos obstáculos observados pela implementação do ensino remoto, os próprios alunos sugeriram a realização de atividades assíncronas e disponibilização permanente das mesmas no sistema, flexibilização dos prazos para entrega das atividades e da cobrança das mesmas, pelo menos durante o momento conturbado da pandemia. Além disso, foram propostas reuniões e palestras para uma aproximação entre a faculdade e os alunos em prol de maior apoio psicológico aos discentes nessa etapa de adaptação ao novo modelo de ensino, assim como uma assistência mais próxima por parte da instituição de ensino em relação ao bem estar do aluno e sua disponibilidade de recursos para que o mesmo consiga acompanhar as aulas sem prejuízos ao seu aprendizado.

Por fim, concluiu-se também que o ensino remoto não influenciou, segundo os próprios alunos via formulário, a realização das atividades, que foram realizadas de acordo com os mesmos, de forma rotineira e sem impacto significativo na produtividade, apesar de apenas $50 \%$ dos alunos conseguirem acompanhar todas as aulas do período. O docente responsável pela disciplina evidenciou a manutenção do ritmo de produção de artigos durante o PLE, assim como o desenvolvimento na escrita e no conhecimento dos alunos de forma semelhante à da época de ensino presencial, indicando que, em suma, apesar dos pontos que necessitam serem melhorados, o ensino remoto foi de grande valia para a continuidade das aulas durante o período de isolamento social e não prejudicaram o rendimento dos participantes, sugerindo que a continuidade da disciplina pelo método virtual pode ser sim uma ideia a ser consolidada após o término do período de isolamento social.

\section{Agradecimentos}

Os autores agradecem à Universidade Federal de Ouro Preto pelo apoio na realização deste trabalho.

\section{REFERÊNCIAS}

GUEDES, Higor V. L. et al. Posicionamento das universidades em relação à cultura do plágio. In: XLVI Congresso Brasileiro de Educação em Engenharia, 2018, Salvador.

Anais. Salvador. Disponível em:

http://www.abenge.org.br/sis submetidos.php?acao=abrir\&evento=COBENGE18\&codigo =COBENGE18 00048 00001194.pdf. Acesso em 12 mar.2021.

OLIVEIRA, Tamires A. B. de; VALENÇA, Kleber F. P. A importância da metodologia científica para o ensino e aprendizagem no ensino superior. In: XII Congresso Nacional de Educação, 2015, Curitiba. Anais. Curitiba. Disponível em:

https://educere.bruc.com.br/arquivo/pdf2015/17807 10482.pdf. Acesso em 12 mar.2021.

PASINI, C.G.D.; CARVALHO, E.; ALMEIDA, L. H. C. A educação híbrida em tempos de pandemia: algumas considerações. Observatório Sócio Econômico da COVID.

UFMS.2020. Disponível em: https://www.ufsm.br/app/uploads/sites/820/2020/06/Textospara-Discussao-09-Educacao-Hibrida-em-Tempos-de-Pandemia.pdf. Acesso em 
SILVA, Paulo H. L. et al. Plágio: impacto na formação acadêmica dos graduandos em engenharia de minas - UFOP. In: XLVIII Congresso Brasileiro de Educação em Engenharia, 2020, Evento online. Anais. Disponível em:

http://www.abenge.org.br/sis submetidos. php?acao=abrir\&evento=COBENGE20\&codigo =COBENGE20 00177 00003107.pdf. Acesso em 10 mar.2021.

VIEIRA, Américo Augusto Nogueira et al. Metodologia Científica no Brasil: ensino e interdisciplinaridade. Educação \& Realidade, Porto Alegre, v. 42, n. 1, p. 237-260, 2017.

\title{
THE INFLUENCE OF E-LEARNING SYSTEM IN THE TEACHING OF SCIENTIFIC METHODOLOGY TO MINING ENGINEERING STUDENTS OF UFOP
}

\begin{abstract}
In the mining engineering course of Federal University of Ouro Preto the discipline of scientific methodology is one of the most important tools for improving scientific writing and presentation of students to academic research. Being fundamental in the development of the student, the teaching of the discipline was significantly affected by the social isolation caused by the pandemic and the consequent implementation of the special school period (PLE), with virtual classes and remotely teaching. Thus, the article aims to evaluate the changes generated by e-learning and its impact on students' development. Through a questionnaire sent after the school period to the students and consultation with the teacher of the discipline, data were collected and the discourse of the collective subject was performed from the answers obtained, highlighting the point of view of the consulted themselves. The students' answers showed limiting factors to the quality of teaching, such as the lack of, internet satisfactory connection, study times and appropriate environments for monitoring activities. In addition, the insecurity caused by social isolation was highlighted, hindering the students' income. However, it was observed that the productivity of the class remained satisfactory, as well as the students themselves confirmed that the PLE did not significantly influence their productivity, even with the increase in the number of disapproved students. Finally, it was suggested the adoption of more asynchronous classes, flexibility of deadlines and closer follow-up by the educational institution in relation to the students, especially in relation to their mental health.
\end{abstract}

Keywords: Scientific Methodology, E-learning, teaching methods. 